\title{
DEVELOPMENT OF A REMOTO CONTROL TYPE WEEDING MACHINE WITH STIRRING CHAINS FOR A PADDY FIELD
}

\author{
HIROAKI UCHIDA and TOMOTAKA FUNAKI \\ Department of Mechanical Engineering, National Institute of Technology, Kisarazu College, 2-11-1 \\ Kiyomidai-higashi, Kisarazu, Chiba 292-0041, Japan \\ E-mail: uchida@maple.m.kisarazu.ac.jp
}

TERUHIRO YAMANO

Xep Entertainment Corporation, Japan

\begin{abstract}
Pesticide-free farming methods are paid attention. There is a method that uses dabbling ducks as a pesticidefree farming method. This is a one of the method to remove of weeds. We release the chicks of a dabbling duck in paddy field. Then they swim and eat weeds. With this principle, weeds are removed. However this method is not easy. So it was considered to remove weeds with a machine. This idea imitates duck swimming. The developed machine floats on the surface of the water using a body board, and has a chain attached to the rear of the machine to stir the paddy field. In addition, the driving unit is an electric type in which the propeller is driven by a motor. The control system of the machine is composed by a raspberry pi, the acquisition of the sensor values are used Arduino. Weeding works were performed 5 times at a pace once a week. As a result, it was confirmed that Monochoria vaginalis of weed was reduced.
\end{abstract}

Keywords : Weeding machine; Paddy field; Organic farming method; GPS

\section{Introduction}

In recent years, agriculture that does not use herbicides has attracted attention because of the growing interest in food safety among consumers and of the reduction of environmental impact. However, in this case weeding work is required because we do not use herbicides. In the past, manual operation was used, but mechanical methods have attracted attention [1]-[3]. In the case of rice cultivation, pesticide-free cultivation is also required. There are reports of image processing [4] and weeding machines [1][5][6] about mechanical methods in rice cultivation. In reports [1],[5] and [6], a wheel or crawler machine moves between rice plants lines and performs weeding works. This method has a problem that the work area is small and it takes a very long time. In addition, there is a method that uses dabbling ducks as a weeding method that does not use an herbicide. In this method, it is effective to control the growth of weeds by controlling the weeds and pests by moving the chicks of a dabbling duck in the paddy field and turbid water by moving. However, there is other problem which must manage animals because of using animals. Weeding in rice cultivation is to remove weeds that impede the growth of rice for up to 1 month after rice planting. During this time, rice plants are small, and when weeds grow, nutrients for rice plants growth are absorbed by weeds. After one month, the rice plants grow well, the influence of weeds is reduced, and the rice has grown sufficiently so that sunlight can't reach the bottom of the paddy field, it is difficult that weeds grow.

In this study, we focus on the weeding method using the chicks of a dabbling duck, and we consider how to make the weed species float, to make the water cloudy and prevent weed growth, by stirring the bottom of the paddy field with a machine. The developed machine floats on the surface of the water using a body board, and has a chain attached to the rear of the machine to stir the paddy field. In addition, the driving unit is an electric type in which the propeller is driven by a motor. We report on the results of weeding works with the developed machine. 


\section{Weeding Machine}

\subsection{Principle of Weeding Mechanism}

From one week to one month after rice planting, rice plant is small, and weeds are easy to grow. During this period, sunlight is likely to hit the water surface and bottom of the paddy field because the rice plant is short and small. Therefore, weeds are easy to grow, and weeds absorb the nutrients that rice plant needs to grow, which hinders the growth of rice plant. Farmers usually use herbicides or weed by hand. In this study, we study weeding methods to prevent weeds from growing or to get rid of weeds because weeding is done in rice cultivation without pesticides. As a method of weeding without pesticides, the method of using dabbling ducks have been practiced conventionally. This method releases the chicks of the dabbling duck to the paddy field, and they eat the weeds and pests to control the obstacles to the growth of the rice plant. The soil of the paddy is stirred by the movement of the dabbling ducks, and the water becomes turbid, thereby preventing the weed to grow. However, because this method uses animals, there are problems as follows: 1) Caring for the dabbling ducks, 2) Installing the electric fences (defense from escape, protection from foreign enemy), 3) Role change in 1 year, 4) Occurring unevenness in weeding effect. In this research, we focus on stirring the soil of paddy field in the farming method, and the weeding machine that we develop has the following functions: 1) Making the paddy field cloudy, 2) Floating the weed species, and preventing roots from growing.

\subsection{Developed Weeding Machine}

Figure 1 shows the weeding method using a weeding machine. Fig. 1 (a) shows the state before weeding work, and Fig. 1 (b) shows the state after weeding work. The condition of the paddy field is that there are 5 to $10 \mathrm{~cm}$ of water depth from one week to one month after the rice planting. In this state, the weeding machine performs the weeding work. Weeding work is carried out with weed seeds being at the bottom of the paddy field and weeds are beginning to grow. By performing weeding work, weeding is done by floating weed seeds and floating weeds that have begun to grow roots. Figure 3 shows a weeding machine with chains which was developed. Table 1 shows the dimensions of the weeding machine. In consideration of the work in the paddy field, the machine body used a body board. The board is $1000 \mathrm{~mm}$ long, $480 \mathrm{~mm}$ wide, and $50 \mathrm{~mm}$ thick. The main body is made of EVA (Ethylene-Vinyl Acetate). The back side of the body is plastic and smooth. A $900 \mathrm{~mm}$ angle bar was fixed to the rear of the body board, and two plastic chains were attached at $150 \mathrm{~mm}$ intervals. The chain length is about 600 $\mathrm{mm}$. Figure 2 shows the chains equipped with machine Because it is made of plastic, it will float in water as it is, so one or two metal hooks were attached to the chain as a weight. As for the drive unit of the machine, the engine unit of the machine that sprays a commercial herbicide is

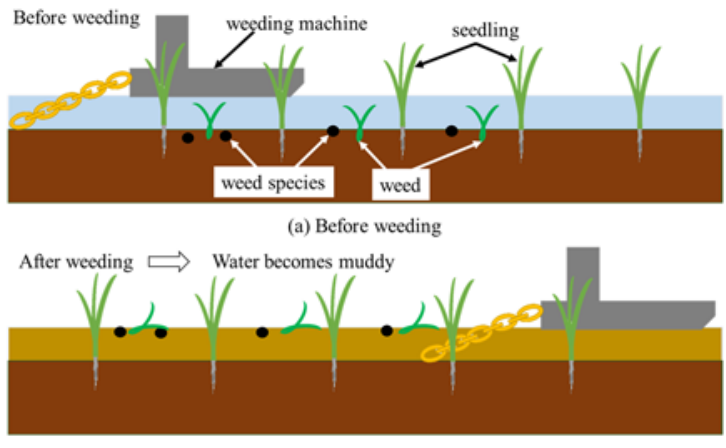

(b) After weeding

Fig.1 Coneept of weeding by machine

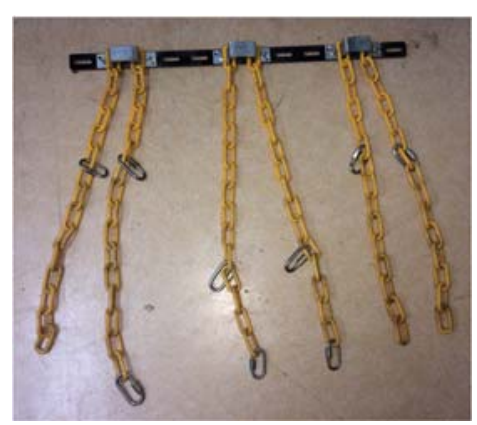

Fig.2 Chains equipped with machine 
replaced by a motor, and forward translational motion is performed by rotating a three-bladed propeller by the rotation of a brushless motor. The drive part and the steering division are shown in Figure 4 and 5, respectively. In addition, a steering unit with $\pm 30 \mathrm{deg}$ movement was attached to the rear of the propeller, and steering was performed by switching the direction of the wind force generated by the propeller.

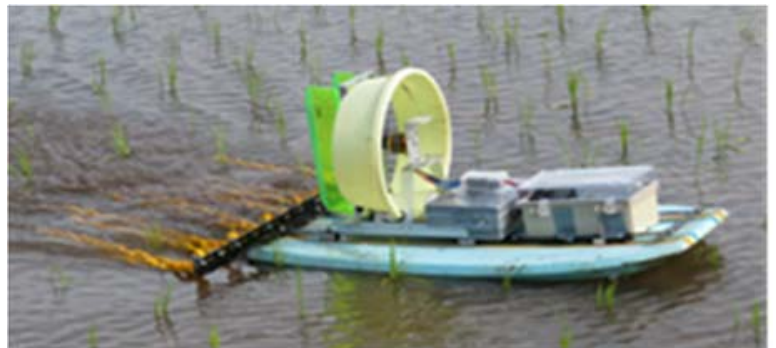

Fig. 3 Weeding machine by developed

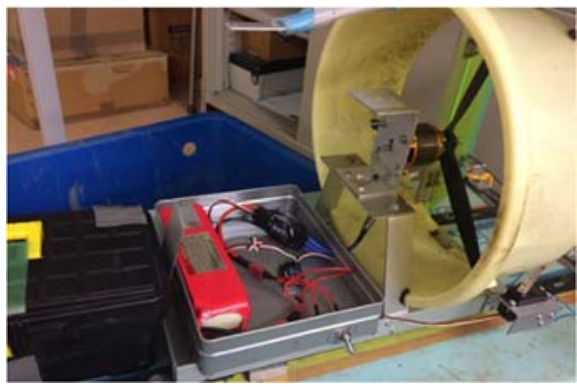

Fig. 4 Drive division
Table 1 Specifications of machine

\begin{tabular}{|l|l|}
\hline Weight & $8.77 \mathrm{~kg}$ \\
\hline Hight & $420 \mathrm{~mm}$ \\
\hline width & $895 \mathrm{~mm}$ \\
\hline length & $1000 \mathrm{~mm}$ \\
\hline
\end{tabular}

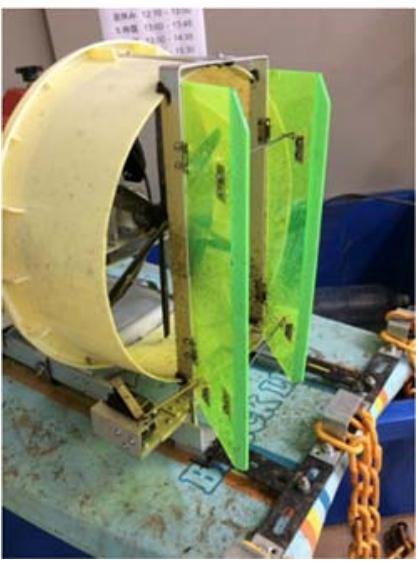

Fig. 5 Steering division

\subsection{Control System}

The machine is operated by human control of $2 \mathrm{ch}$, where one is the drive motor and the other is the steering servomotor, using a transmitter and a receiver. A schematic diagram of the control

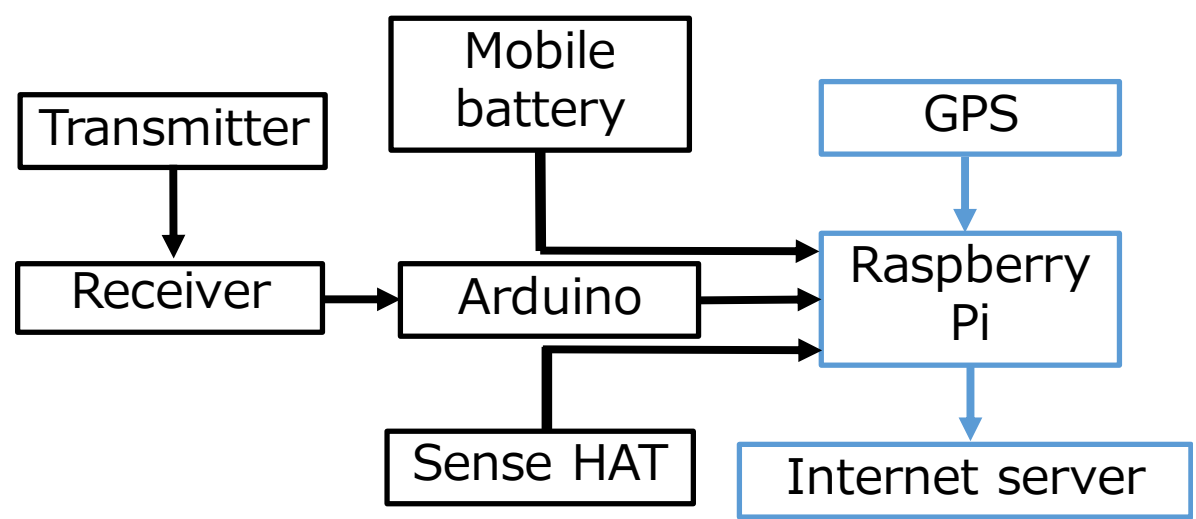

Fig.6 Control system 
system is shown in Figure 6. The power sources of the control system are mobile batteries. The input values of the transmitter are got by Arduino, acceleration data is got by Sense HAT. Arduino is used because Sense HAT uses all Raspberry Pi's GPIO pins. Also, their data are stored in Raspberry Pi. The machine's position information is taken into Raspberry Pi in 1s using GPS sensor. Raspberry Pi can be operated at the operator's hand via SSH connection and can check the work status. The preservation system is built using Python.

\subsection{Mathematical Model of Machine}

In this section, we consider the mathematical model of the machine. Figure 7 shows the mathematical model of the machine. The machine's traveling direction is $y$, the lateral direction is $x$, and the rotational angle around the center of gravity is $\theta$. The machine's mass is $M$, the moment of inertia around the center of gravity is $I_{z}$, the propulsive force by the motor is $F$, and its $x$ and $y$ direction components are $F_{x}$ and $F_{y}$, respectively. Also, $d$ is the distance from the position of the center of gravity to the steering part of the machine. $\theta_{r}$ indicates the steering angle of the rudder. Machines are affected by the resistance of rice plants in the paddy field, of floating matter on the water surface, and of wind during work. $F_{d x}$ and $F_{d y}$ are components of this resistance in the $x$ and $y$ directions, and $\tau_{d}$ is the torque due to these resistances. The equation of motion around the center of gravity of the machine is equation (1).

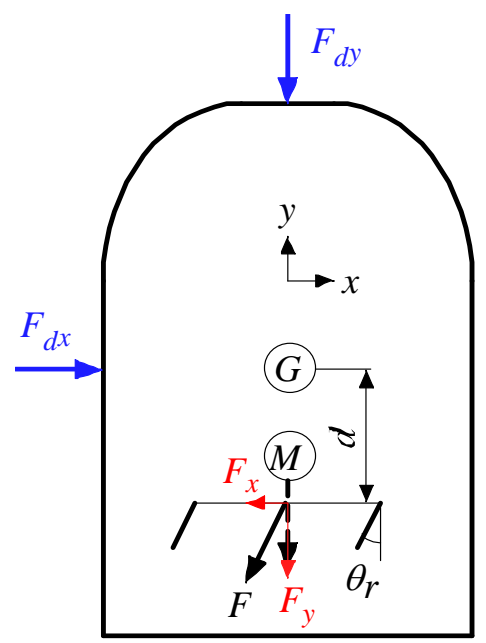

Motion Equations

$$
\left\{\begin{array}{c}
M \ddot{x}=F \sin \theta_{r}-F_{d x} \\
M \ddot{y}=F \cos \theta_{r}-F_{d y} \\
I_{z} \ddot{\theta}=F \sin \theta_{r} \times d-\tau_{d}
\end{array}\right.
$$

Fig.7 Mathematical model

\section{Experiments of Weeding}

Weeding work was performed by the weeding machine we made. Specifically, rice planting was carried out on May 25, 2018, and a total of five tests were conducted on 5/28,6/1, 6/8,6/18, and $6 / 25$. The area of the paddy field was about $750 \mathrm{~m}^{2}$ and the working time was about 45 minutes. In this work time, all the charge capacity of one battery was consumed. The situation at work is shown in Figure 8. Fig. 8 (a) shows 6/1, Fig. (b) shows 6/8, and Fig. (c) shows 6/18. The heights of the rice plants were 100 to $200 \mathrm{~mm}, 200$ to $400 \mathrm{~mm}$, and 300 to $500 \mathrm{~mm}$, respectively. At the time of work, the machine pushes down the rice plants, so the rice plants remain fallen over the water surface but returns to the standing condition as well as after planting the rice, at next day. One month after rice planting, rice plants grow, and it becomes impossible to move the machine. Figure 9 compares the condition of weeds in the paddy field where weeding work and the field where weeding work was not done. Two months after planting rice, it is about one month after weeding work. In Fig. 9(a), Monochoria vaginalis of weed grew, but in the weeding paddy field, 


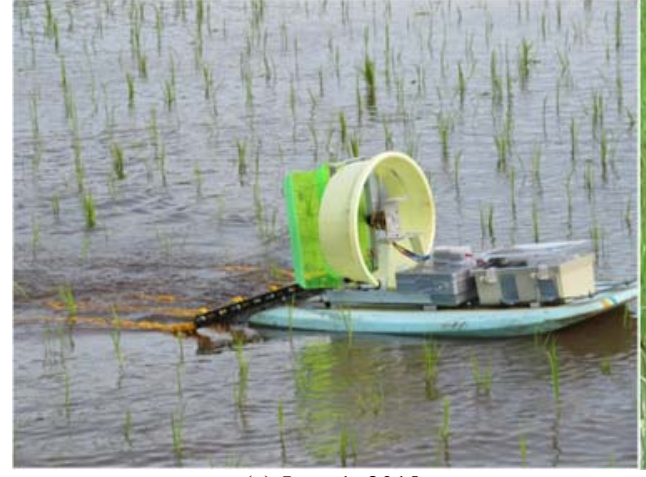

(a) June 1, 2018

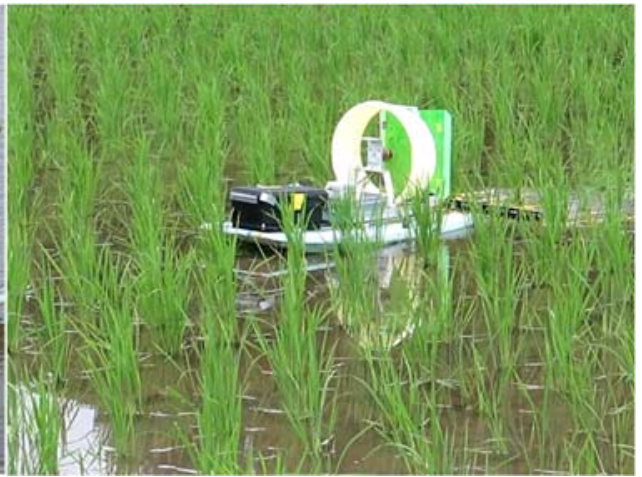

(b) June 8, 2018

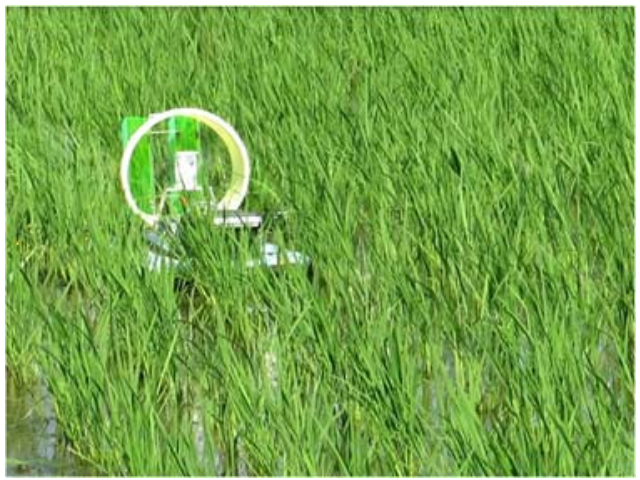

(c) June 18, 2018

Fig.8 State of weeding works

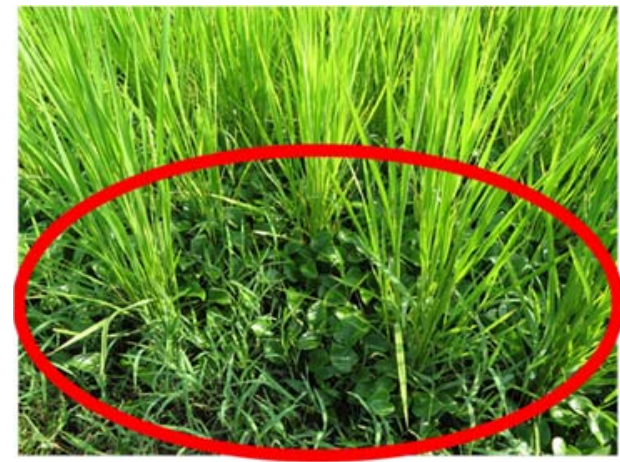

(a) without weeding

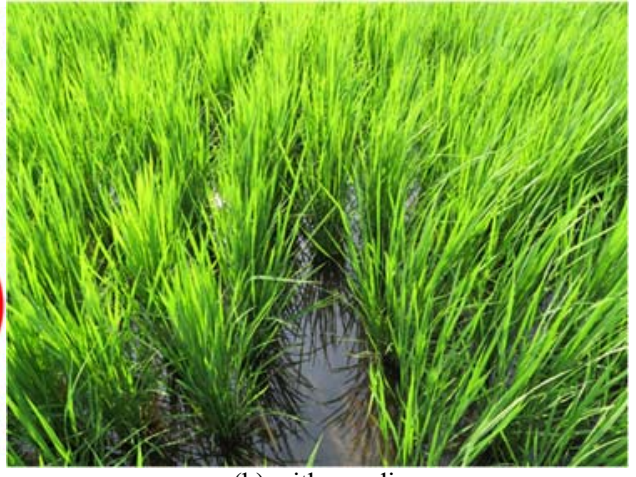

(b) with weeding

Fig.9 Comparison of paddy fields that weeded and not weeded

we could reduce the incidence of Monochoria vaginalis. Next, Figure 10 shows the locus of GPS data when working on 6/18. This is the result of plotting GPS data on Google Earth. Although an error of about $2 \mathrm{~m}$ has occurred, it can be seen that the work was performed on the entire paddy field. Figure 11 shows the travel distance. In Fig.11, $x$-axis represents working time. The machine moved about $900 \mathrm{~m}$ in about $2700 \mathrm{~s}$ (45 minutes) work. Figure 11 shows the machine's driving force controlled by the operator from the transmitter to the motor amplifier, and the speed obtained by the first-order low-pass filter $(T=10)$ in equation (2) using the machine's travel distance in Fig.11. Figure 12(a) shows the input pulse from the transmitter, and Fig.12(b) shows the velocity. The speed was operating at 0.2 to $0.6 \mathrm{~m} / \mathrm{s}$, and the average speed was $0.33 \mathrm{~m} / \mathrm{s}$. The number of input pulses at the time of motor driving was changing from 1250 to 1350 . Now, the weeding work is a state where weeding of the working area is based on the 


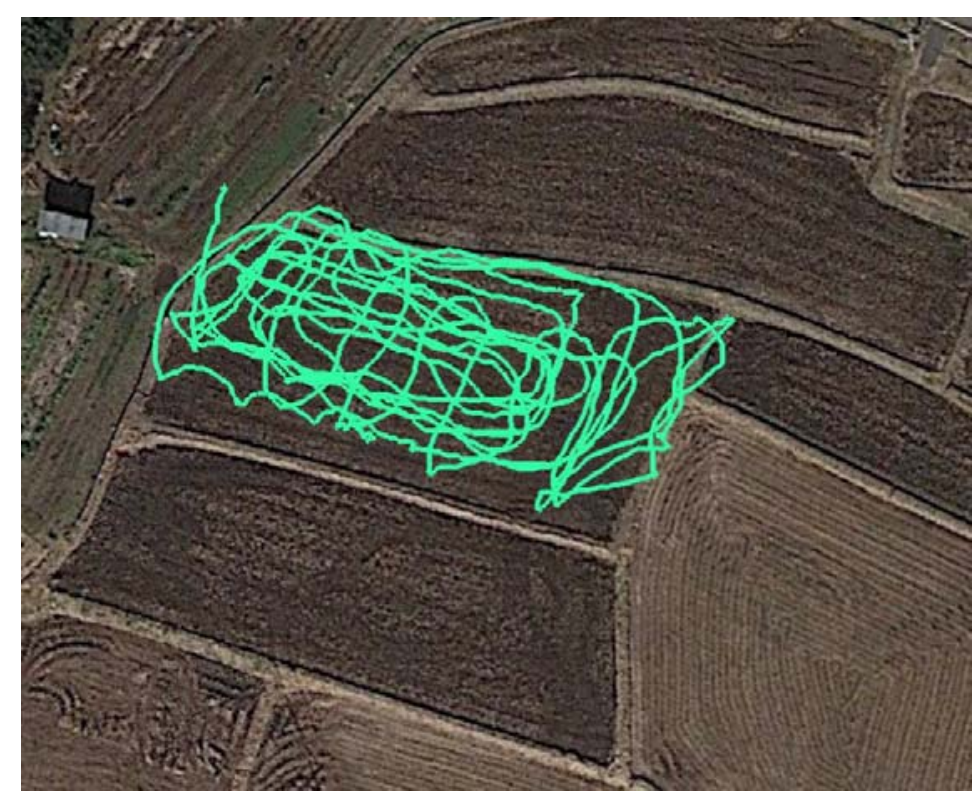

Fig.10 Orbits of weeding robot in June 18, 2018.

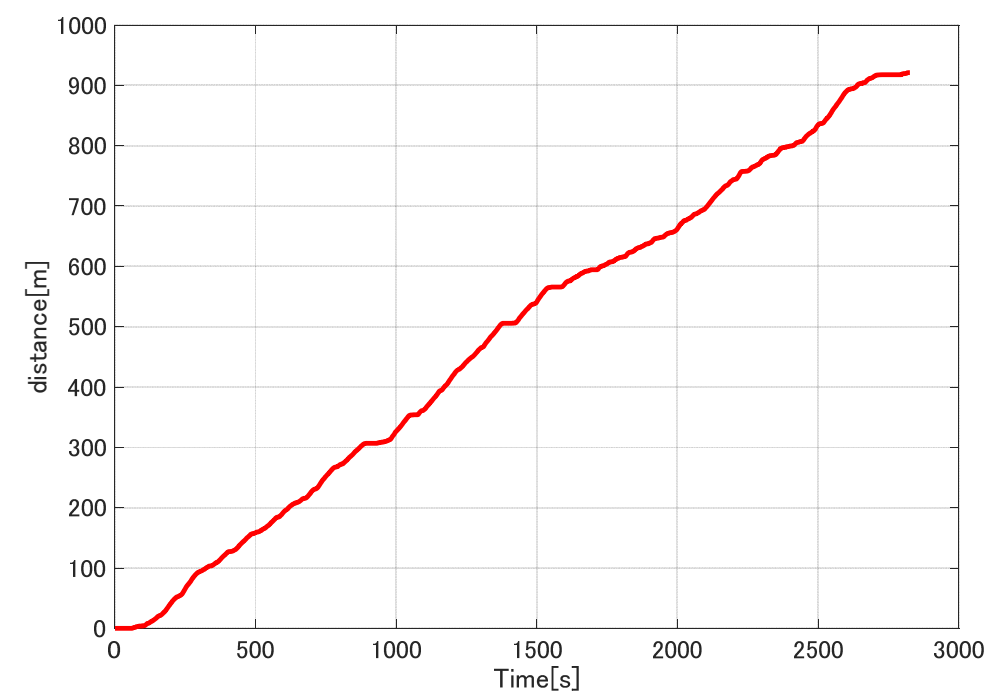

Fig.11 Working distance by GPS data

memory of the pilot, and in the future we aim to present the working trajectory to the pilot or to drive automatically.

$$
G(s)=\frac{1}{1+T s}
$$

From this equation, we will consider the relationship between the inputs and the response waveform of the speed during weeding work in Fig. 11. Since Fig.11 shows data only for the machine's traveling direction, it only shows the relationship of the traveling direction $y$ in Eq. (2). Since the input has a dimension of acceleration, the pulse of the input always generates a propulsive force at 1250 to 1350 , but the movement speed is in the range of 0.2 to $0.6 \mathrm{~m} / \mathrm{s}$. As 


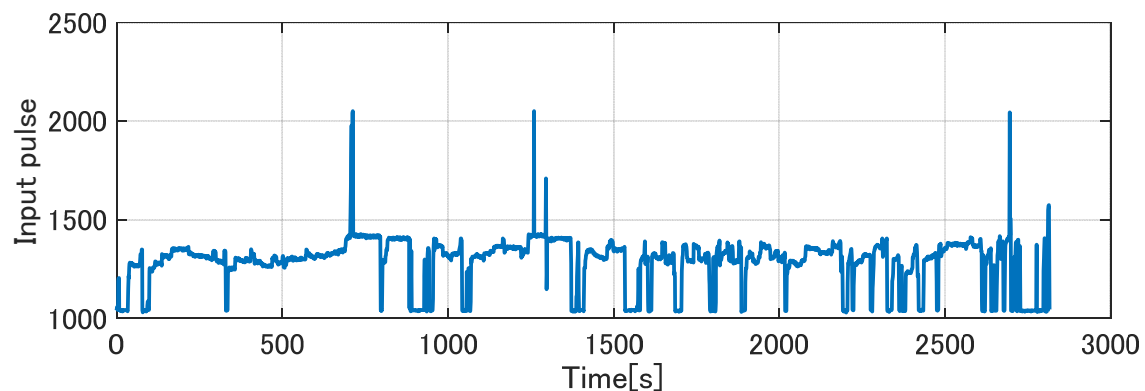

(a) Control Input

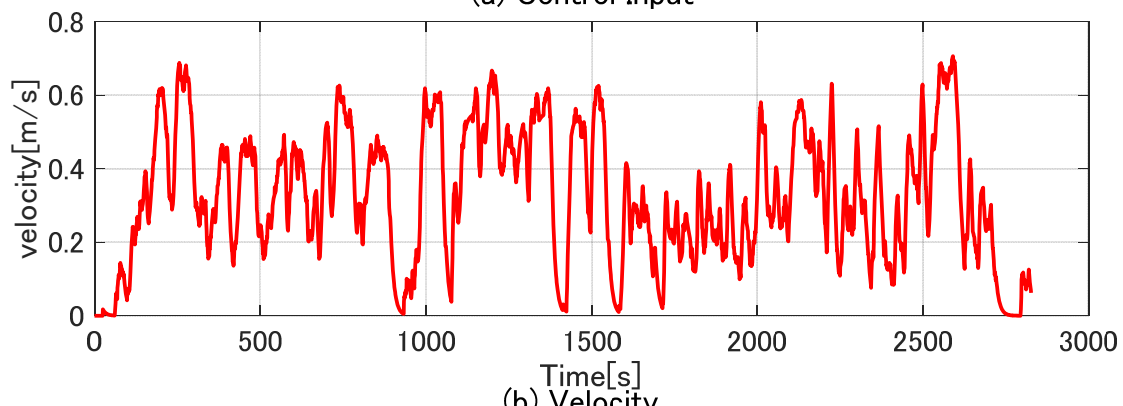

(b) Velocitv

Fig.12 Control input and velocity of the robot

it is desired from the farmer to work $1000 \mathrm{~m}^{2}$ (10 are) in about 60 minutes, it achieved work efficiency close to it. From this, the resistance force $F_{d y}$ works to the machine. Since machine's acceleration is measured in Sense HAT, we also consider acceleration data. Figure 13 shows the coordinate system of acceleration and angular velocity in Sense HAT. It differs from the coordinate system shown in Fig.12 by the mathematical model of the machine. Fig.14 shows the time response in acceleration in the traveling direction. In the figure, the blue dashed line is the acquired data, and the data processed by the first-order low-pass filter of Eq. (1) is shown by the red solid line. The average value of the filtered data is $0.01 \mathrm{~m} / \mathrm{s}$, and a constant acceleration is output in the traveling direction. This also indicates that $F_{d y}$ of resistance is acting during weeding work.

\section{Conclusion}

In this study, we developed a weeding machine that weeds in a paddy field with a water level of 5 to $10 \mathrm{~cm}$ between 5 days to 1 month after rice planting and weeded. As a result, the following results were obtained.

1. The body board was used for the machine body and the propulsion force was generated by rotating the propeller attached to the motor. The machine was steered by a rudder mechanism.

2. $60 \mathrm{~cm}$ long chains were attached to the rear of the machine and weeding works were performed 5 times at a pace once a week. As a result, it was confirmed that Monochoria vaginalis of weed was reduced.

3. We analyzed the data of GPS sensor and Sense HAT mounted on the machine and confirmed that the resistance force works to the machine.

In the future, aiming at automatic operation of the machine, we will develop a control system and use a mathematical model of the machine to examine a feedback control method to reduce the influence of resistance. 


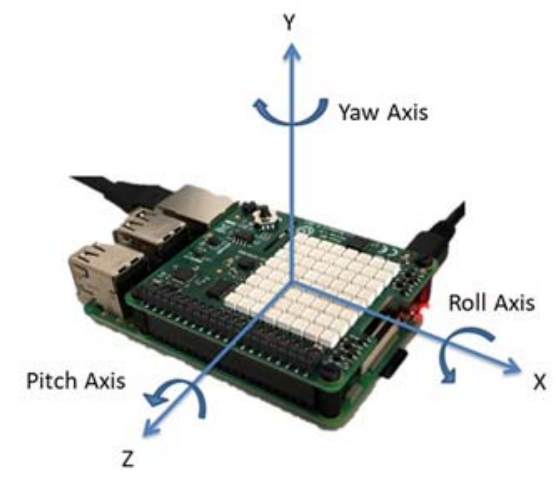

Fig.13 axes of sense HAT

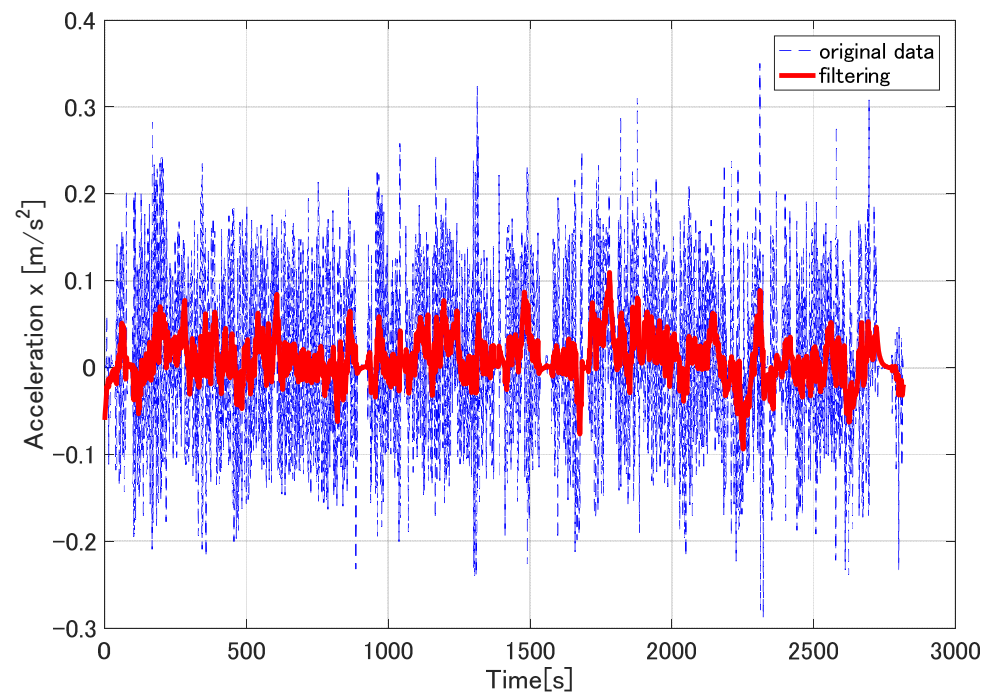

Fig.14 Time response of acceleration obtained by sense HAT in advanced direction

\section{References}

1. T.Mitsui, T. Kobayshi, T. Kagiya, A. Inaba and S. Ooba, Verification of a Weeding Robot "AIGAMO-ROBOT" for Paddy Fields, J. of Robotics and Mechatronics, 20, 2(2008), pp.228-233.

2. K. Tamaki, Y. Nagasaka, K. Nishiwaki, M. Saito, Y. Kikuchi and K. Motobayashi, A Robot System for Paddy Field Farming in Japan, $4^{\text {th }}$ IFAC Conf. on Modelling and Control in Agriculture, Horticulture and Post Harvest Industry, 2013, pp 143-147.

3. Y. Liu, N. Noguchi and L. Liang, Development of a positioning system using UAV-based computer vision for an airboat navigation in paddy field, Computers and Electronics in Agriculture, 162, 2019, pp.126-133.

4. K. H. Choi, S. K. Han, S. H. Han, K-H. Park, K-S. Kim and S. Kim, Morphology-based guidance line extraction for an autonomous weeding robot in paddy fields, Computers and Electronics in Agriculture, 113, 2015, pp.266-274.

5. H.Sori, H. Inoue, H. Hatta and Y. Ando, Effect for a Paddy Weeding Robot in Wet Rice Culture, J. of Robotics and Mechatronics, 30, 2(2018), pp.198-205.

6. K. Kameyama, Y. Umeda and Y. Hashimoto., Simulation and experiment study for the navigation of the small autonomous weeding robot in paddy fields, Proc. of the SICE Annual Conference 2013, 2013, pp.1612-1617. 